\title{
Diurnal Rhythmicity and Hypothalamic Deficits in Glucose Utilization in Aged Ovariectomized Rats
}

\author{
Phyllis M. Wise, ${ }^{1}$ Richard C. Walovitch, ${ }^{2, a}$ Ilene R. Cohen, ${ }^{1}$ Nancy G. Weiland, ${ }^{1}$ and Edythe D. London ${ }^{2}$ \\ 'Department of Physiology, School of Medicine, University of Maryland, Baltimore, Maryland 21201, and \\ ${ }^{2}$ Neuropharmacology Laboratory, Addiction Research Center, National Institute on Drug Abuse, Baltimore, Maryland \\ 21224
}

Aging is associated with a loss of cyclic gonadotropin release in female animals. This deficit may reflect dampened circadian rhythmicity of neuroendocrine events and/or altered function in hypothalamic nuclei important to regulation of cyclic female reproduction. The purpose of this study was to determine if diurnal periodicity and glucose metabolism in the hypothalamus are altered with age and whether such changes could help to explain the age-related deficits in gonadotropin release.

Young (3-4-month-old) and old (18-21-month-old) rats were ovariectomized and subjected to the 2-deoxy-D-1-14 Cglucose technique to measure rates of cerebral glucose utilization (GU), an index of neural function (Sokoloff et al., 1977 ) in various brain areas and in the pineal gland. We measured GU during the light (1400 hours) and the dark ( 2200 hours) in 17 anatomical regions including the following hypothalamic areas: medial preoptic nucleus, suprachiasmatic preoptic nucleus, suprachiasmatic nucleus, paraventricular nucleus, arcuate nucleus, and median eminence. Serum concentrations of luteinizing hormone (LH) and prolactin were measured in the same rats to determine the effect of age on both of these hormones.

Diurnal periodicity of GU was observed in the suprachiasmatic nucleus and the pineal gland in young and old rats. Although there was no age difference in GU of the pineal gland, GU was reduced during the light and dark in the suprachiasmatic nucleus and all other hypothalamic areas examined except the suprachiasmatic preoptic nucleus and the median eminence. Ovariectomy induced an attenuated increase in concentrations of $\mathrm{LH}$ in old, compared to young rats. Serum concentrations of prolactin were the same in both young and old ovariectomized rats.

The results indicate that the functional activity of several specific hypothalamic nuclei important to luteinizing hormone-release hormone (LHRH) release and reproductive function declines with age. In particular, diminished GU in the suprachiasmatic nucleus may reflect changes in neural function in this important pacemaker area of the brain.

\footnotetext{
Received Apr. 25, 1986; revised Apr. 27, 1987; accepted Apr. 28, 1987

This work was supported in part by NIH Grants AG-02224 and HD-15955 and Research Career Development Award AG-00168 to P.M.W., and by NIH Research Scientist Awards AG-0535 I to I.R.C. and AG-05357 to N.G.W. We wish to thank Drs. G. D. Niswender, L. E. Reichert, and the NIADDK Hormone Distribution Program for LH antibody, ovine LH for iodination, and LH-RP2 standard and prolactin radioimmunoassay kit, respectively. We thank Klara Roth for her excellent technical assistance.

Correspondence should be addressed to Phyllis $M$. Wise at the above address.

a Present address: New England Nuclear Corp., Boston, MA 02118.

Copyright (C) 1987 Society for Neuroscience $0270-6474 / 87 / 113469-05 \$ 02.00 / 0$
}

The age-related loss of female reproductive function is associated with deficiencies in hypothalamic neurochemical markers. Turnover rates of catecholamines (Finch, 1973; Estes and Simpkins, 1984) and serotonin (Simpkins et al., 1977) vary with senescence, and these changes have been associated with alterations in hypothalamic releasing hormones that regulate gonadotropin release (Wise and Ratner, 1980). Female reproductive cyclicity has a circadian basis (Everett et al., 1949) that depends upon the integrity of the suprachiasmatic nucleus (Brown-Grant and Raisman, 1977). Changes in this important pacemaker area may account for altered circadian rhythms in running behavior (Mosko et al., 1980), sleep activity (Miller and Bartus, 1982), hormone concentrations (Bremner et al., 1983), and activities of neurotransmitters (Wise, 1984; Cohen-Becker and Wise, 1985).

Previous studies have indicated that local rates of glucose utilization (GU), an index of ccrcbral activity (Sokoloff, 1983), decline with age in various brain areas of male rats (Smith et al., 1980; London et al., 1981). However, the effect of age on GU rates in discrete hypothalamic areas involved in regulation of reproductive function has not yet been examined. A diurnal rhythm in GU also has been demonstrated in the suprachiasmatic nucleus of young male rats (Schwartz et al., 1980); however, it is unknown whether the diurnal rhythm of GU is maintained in this pacemaker area during aging.

The purpose of the present study, therefore, was to determine if diurnal periodicity of $\mathrm{GU}$ within the suprachiasmatic nucleus was lost as a function of age. It was also of interest to determine whether the reported age-related deficits in hypothalamic neurochemical markers are associated with overall changes in function, as indicated by rates of $\mathrm{GU}$.

\section{Materials and Methods}

Animals. Young (3-4-month-old) and old (18-21-month-old) female rats were purchased from Zivic-Miller Laboratories (Allison Park, PA) They were housed in temperature- $\left(22-24^{\circ} \mathrm{C}\right)$ and light- $(14: 10$ light : dark cycle; lights on at 0400 hours) controlled rooms and were given food and water ad libitum. Rats were ovariectomized to avoid the potential actions of fluctuating steroids on GU (Sokoloff, 1983; Namba and Sokoloff, 1984) and were used to assess GU $9 \mathrm{~d}$ later. Hormone concentrations and $\mathrm{GU}$ were determined in freely moving rats during the light and dark periods, at 1400 and 2200 hours, respectively. Blood was collected under dim red light illumination ( $40 \mathrm{~W}$ ) during the dark interval. On the day of the experiment, at 1345 or 2145 hours, a 0.5 $\mathrm{ml}$ blood sample was taken from the atrial cannula to assess serum luteinizing hormone ( $\mathrm{LH})$ and prolactin concentrations.

$G U$ determinations. GU was determined by the autoradiographic ${ }^{14} \mathrm{C}-$ 2-deoxy-D-glucose procedure (Sokoloff et al., 1977). [ $\left.{ }^{14} \mathrm{C}\right] \mathrm{DG}$ (sp act, $55-57 \mathrm{mCi} / \mathrm{mmol}$; New England Nuclear, Boston, MA) was dried down, resuspended in $0.9 \% \mathrm{NaCl}$, and was rechromatographed to check the 
Table 1. ${ }^{14} \mathrm{C}$ concentrations in plasma withdrawn simultaneously from the jugular vein and femoral artery after a bolus injection of radiotracer into the jugular vein

\begin{tabular}{ccc}
$\begin{array}{c}\text { Time } \\
(\text { min) }\end{array}$ & Artery $(\mathrm{cpm})$ & Vein $(\mathrm{cpm})$ \\
\hline 0.17 & $156,239 \pm 17,822^{a}$ & $188,180 \pm 20,263$ \\
0.25 & $102,374 \pm 10,322$ & $111,714 \pm 6146$ \\
0.50 & $97,948 \pm 6357$ & $100,521 \pm 6009$ \\
0.75 & $93,447 \pm 5759$ & $88,751 \pm 2739$ \\
1.0 & $88,624 \pm 5148$ & $76,077 \pm 6560$ \\
2.0 & $80,150 \pm 6461$ & $64,260 \pm 6253$ \\
3.0 & $68,210 \pm 7470$ & $57,254 \pm 5247$ \\
5.0 & $55,802 \pm 6744$ & $50,538 \pm 3901$ \\
7.5 & $44,012 \pm 4806$ & $39,584 \pm 2829$ \\
10.0 & $38,776 \pm 6257$ & $35,372 \pm 2446$ \\
15.0 & $36,226 \pm 5319$ & $32,283 \pm 2852$ \\
25.0 & $29,332 \pm 3937$ & $25,814 \pm 2946$ \\
35.0 & $21,290 \pm 2978$ & $19,950 \pm 2016$ \\
45.0 & $16,500 \pm 2438$ & $13,412 \pm 1875$ \\
\hline
\end{tabular}

Mean $\pm \mathrm{SE}(n=4)$

purity. The following modifications allowed us to determine GU in unrestrained rats. Approximately $24 \mathrm{hr}$ prior to experimentation, the external jugular vein was cannulated to the level of the right atrium under ether anesthesia using polyethylene tubing (PE 50; OD $=0.96$ $\mathrm{mm}$, length $=4 \mathrm{in}$.). At 1400 or 2200 hours, $\left[{ }^{14} \mathrm{C}\right] \mathrm{DG}$ was injected into the jugular vein cannula as a bolus at a dose of $100 \mu \mathrm{Ci} / \mathrm{kg}$ body weight. The cannula was immediately flushed with saline, and timed samples of mixed venous blood from the right atrium were collected from the same cannula for measurement of ${ }^{14} \mathrm{C}-\mathrm{DG}$ and glucose concentrations. Mixed venous blood samples $(200 \mu 1)$ were drawn using a syringe, and the blood volume was replaced with an equal volume of $0.9 \%$ saline after each sampling. We calculated that each $200 \mu$ l blood sample was effectively diluted with $60 \mu \mathrm{l}$ saline in the dead space of the 4 in. cannula and the syringe; therefore all ${ }^{14} \mathrm{C}-\mathrm{DG}$ and glucose values were multiplied by a correction factor of 1.4 . Immediately after the $45 \mathrm{~min}$ blood sample, pentobarbital $(75 \mathrm{mg} / \mathrm{kg})$ was administered via the right atrial cannula, and the rats were decapitated. Cerebral glucose utilization has been determined previously using mixed venous blood samples (Bryan et al., 1983).

We tested whether the same cannula could be used for injection of $\left[{ }^{14} \mathrm{C}\right] D G$ and for collection of blood samples without contamination from the original bolus injection of tracer by performing the following preliminary experiment. The jugular vein and the femoral artery of rats were cannulated under pentobarbital anesthesia $(30 \mathrm{mg} / \mathrm{kg})$. A bolus injection of $\left[{ }^{14} \mathrm{C}\right] \mathrm{DG}$ was injected into the jugular vein and timed blood samples were withdrawn simultaneously from the venous and arterial cannulae. Table 1 shows that the concentration of ${ }^{14} \mathrm{C}$ was the same in both cannulae at all sampling periods.

Tissue preparation, quantitative autoradiographic densitometry, and calculation of $G U$. Brains were removed, frozen, sectioned, and prepared for autoradiography as described previously (Sokoloff et al., 1977). Sections of brain and ${ }^{14} \mathrm{C}$-methylmethacrylate standards were apposed to Kodak SB5 film for $8 \mathrm{~d}$. The optical densities in regions of autoradiograms corresponding to 17 brain structures were determined using a Leitz Orthoplan microscope with MPV microdensitometer (Model 560/ DADS; E. Leitz, Rockleigh, NJ). The following brain areas were identified by comparing autoradiograms to a standard stereotaxic atlas (Paxinos and Watson, 1982): frontoparietal cortex, motor region; frontoparietal cortex, somatosensory region; corpus callosum; striatum; medial preoptic nucleus; suprachiasmatic preoptic nucleus; suprachiasmatic nucleus; paraventricular nucleus; medial amygdala; cortical amygdala; arcuate nucleus; median eminence-medial internal aspect; median eminence-medial external aspect; median eminence-lateral internal aspect; median eminence-lateral external aspect; hippocampus; and pineal gland. Each brain region was read bilaterally from at least 6 sections per brain. Thus, at least 12 readings of light transmittance $(\% T)$ were recorded for each structure per animal. They were averaged for each structure, and

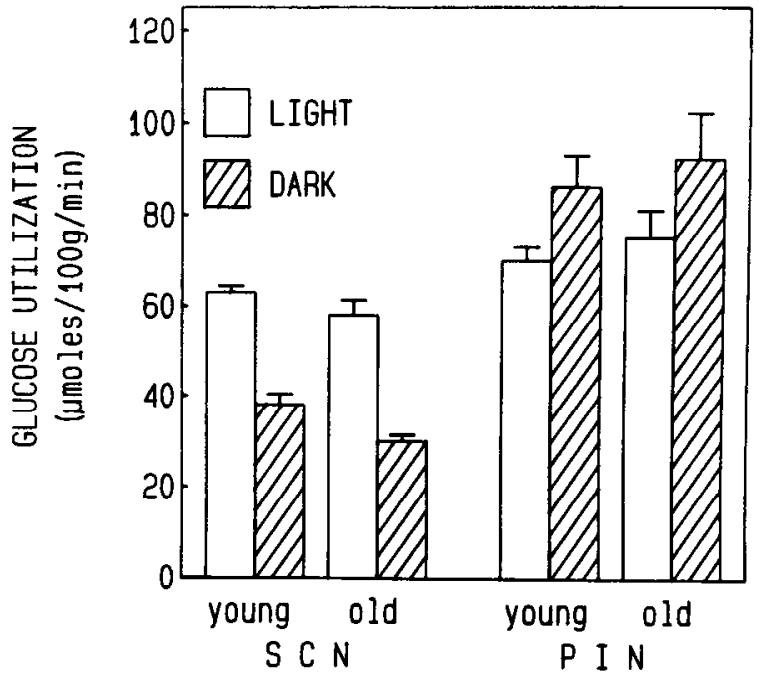

Figure 1. Glucose utilization in suprachiasmatic nucleus $(S C N)$ and the pineal gland $(P I N)$ of young and old ovariectomized rats during the light and the dark.

the average optical density was calculated as the $\log _{10}(1 / T)$. Autoradiograms were read at $20 \times$ magnification. The reticule area used was $0.04 \mathrm{~mm}^{2}$, which allowed the median eminence to be subdivided into regions. The median eminence was subdivided to correspond to those areas described by Fuxe and coworkers (1978), who suggested that each area of median eminence may have a different neurohumoral and neuroendocrine regulatory function.

Rates of GU were calculated from estimates of radioactivity in the selected brain regions and plasma concentrations of $\left[{ }^{14} \mathrm{C}\right] \mathrm{DG}$ and glucose, using an operational equation, as described previously (Sokoloff et al., 1977). The values of the lumped constant used for young and old rats were 0.502 and 0.435 , respectively. These values were obtained from linear regression of reported values for 3-, 12-, and 24-monthold male Fischer 344 rats (Takei et al., 1986). It should be emphasized that these values of the lumped constant were obtained in studies performed in males and were used in this study with the assumption that similar changes occur in aging female Sprague-Dawley rats.

$L H$ and prolactin radioimmunoassays. Concentrations of serum $\mathrm{LH}$ were determined by radioimmunoassay (Niswender et al., 1969). LH antibody (GDN-15) was generously provided by Dr. Gordon Niswender, ovine LH for iodination by Dr. Leo Reichert, and LH-RP2 standard by the NIADDK Rat Pituitary Hormone Distribution Program. This LH standard is 63 times more potent than LH-RP1. Rat prolactin (rPRL-RP2) concentrations were determined by homologous doubleantibody procedures (Selmanoff and Wise, 1981). Antibody, standards, and hormone used to prepare the iodinated ligand were provided by the NIADDK Rat Pituitary Hormone Distribution Program. rPRL-RP2 is 2.8 times more potent than rPRL-RP1.

Statistical analysis. Effects of age and time of day on GU values and hormone concentrations were analyzed by 2 -way analysis of variance. The criterion for significance statements was $p \leq 0.05$.

\section{Results}

GU values (see Table 2) were significantly higher in the suprachiasmatic nucleus $(p<0.001)$ and lower in the pineal gland $(p<0.03)$ in the light compared to the dark (Fig. 1). In addition, the suprachiasmatic nucleus exhibited decreased values in aged compared to young rats during both the light and dark, whereas the pineal gland exhibited no age-related difference during the light or dark period.

We observed age-related decreases in GU in several other hypothalamic areas that are involved in reproductive function. $\mathrm{GU}$ in the medial preoptic nucleus, paraventricular nucleus, cortical and medial amygdala, and arcuate nucleus were lower in old than in young rats. In striking contrast, none of the aspects 
Table 2. Effects of age and time of day on $\mathrm{GU}(\mu \mathrm{mol} / 100 \mathrm{gm} / \mathrm{min})$

\begin{tabular}{|c|c|c|c|c|c|c|c|}
\hline \multirow[b]{2}{*}{ Brain area } & \multicolumn{2}{|c|}{ Young (3-4 months) } & \multicolumn{2}{|c|}{ Old (18-21 months) } & \multicolumn{3}{|c|}{ Values of $p$ from ANOVA } \\
\hline & Light & Dark & Light & Dark & Age & Time & $\mathrm{A} \times \mathrm{T}$ \\
\hline Frontoparietal cortex, motor area & $107 \pm 4.1^{a}$ & $105 \pm 5.0$ & $88 \pm 3.9$ & $94 \pm 4.1$ & 0.008 & NS & NS \\
\hline Frontoparietal cortex, somatosensory area & $109 \pm 5.3$ & $109 \pm 2.9$ & $99 \pm 3.5$ & $102 \pm 3.4$ & 0.04 & NS & NS \\
\hline Corpus callosum & $34 \pm 2.1$ & $31 \pm 2.1$ & $28 \pm 1.6$ & $25 \pm 2.8$ & 0.02 & NS & NS \\
\hline Striatum & $96 \pm 2.9$ & $88 \pm 4.3$ & $65 \pm 3.3$ & $74 \pm 3.1$ & 0.001 & NS & 0.03 \\
\hline Medial preoptic nucleus & $50 \pm 4.0$ & $48 \pm 6.0$ & $40 \pm 3.0$ & $40 \pm 2.6$ & 0.04 & NS & NS \\
\hline Suprachiasmatic prcoptic nucleus & $39 \pm 2.4$ & $37 \pm 2.8$ & $39 \pm 3.6$ & $33 \pm 2.6$ & $\mathbf{N S}^{h}$ & NS & NS \\
\hline Suprachiasmatic nucleus & $63 \pm 1.4$ & $38 \pm 2.3$ & $58 \pm 3.3$ & $30 \pm 1.4$ & 0.02 & 0.001 & NS \\
\hline Paraventricular nucleus & $48 \pm 4.6$ & $49 \pm 5.1$ & $39 \pm 1.7$ & $37 \pm 1.0$ & 0.02 & NS & NS \\
\hline Medial amygdala & $51 \pm 2.4$ & $48 \pm 6.1$ & $38 \pm 3.1$ & $40 \pm 3.0$ & 0.02 & NS & NS \\
\hline Cortical amygdala & $39 \pm 1.6$ & $39 \pm 1.5$ & $34 \pm 3.9$ & $30 \pm 2.9$ & 0.02 & NS & NS \\
\hline Arcuate nucleus & $40 \pm 1.0$ & $38 \pm 3.2$ & $39 \pm 2.9$ & $32 \pm 1.6$ & $\mathbf{N S}^{n}$ & NS & NS \\
\hline Median eminence, lateral internal & $44 \pm 2.9$ & $42 \pm 3.2$ & $50 \pm 4.8$ & $42 \pm 3.0$ & NS & NS & NS \\
\hline Median eminence, medial internal & $44+2.7$ & $43 \pm 1.9$ & $43 \pm 8.8$ & $42 \pm 4.6$ & NS & NS & NS \\
\hline Median eminence, lateral external & $46 \pm 2.3$ & $46 \pm 3.3$ & $52 \pm 4.5$ & $45 \pm 4.1$ & NS & NS & NS \\
\hline Median eminence, medial external & $48 \pm 2.7$ & $46 \pm 3.2$ & $53 \pm 3.8$ & $47 \pm 5.1$ & NS & NS & NS \\
\hline Hippocampus & $56 \pm 2.3$ & $59 \pm 3.3$ & $52 \pm 6.2$ & $49 \pm 2.8$ & 0.002 & NS & NS \\
\hline Pineal gland & $70 \pm 3.0$ & $86 \pm 6.7$ & $75 \pm 6.0$ & $92 \pm 10.1$ & NS & 0.03 & NS \\
\hline
\end{tabular}

Mean \pm SE $(n=4-6)$.

${ }^{\circ}$ These brain areas exhibited significant age-related changes when the lumped constant was not corrected for age.

of the median eminence demonstrated age-related differences during the light or dark (Table 2).

Decreases were observed in GU in several nonhypothalamic areas, including the motor and somatosensory areas of the cerebral cortex, corpus callosum, and striatum (Table 2). There was no difference between GU values during the light and dark in any of the above brain structures; however, there was a significant interaction between age and time of day in the striatum $(p<0.03)$. The interaction reflected a nonsignificant tendency for $\mathrm{GU}$ to be higher during the light phase in young rats and lower during the light in old rats.

LH concentrations were significantly lower in old compared to young ovariectomized rats, whereas prolactin concentrations did not exhibit age-related differences (Table 3).

\section{Discussion}

We observed a diurnal rhythm in GU in the suprachiasmatic nucleus, in agreement with Schwartz et al. (1980), who observed a circadian rhythm that was entrained to the light cycle in male rats. Values of GU continued to exhibit a diurnal rhythm in old female rats, but values were lower during both the light and dark. Decrements in GU in the suprachiasmatic nucleus suggest an age-related decrease in oxidative metabolism, which may either reflect or contribute to specific functional losses in this important pacemaker nucleus. Several circadian functions that are regulated by the suprachiasmatic nucleus are altered in se- nescence. The circadian rhythm in testosterone disappears in elderly men (Bremner et al., 1983) and senile male rats (Simpkins et al., 1981). Circadian rhythmicity in locomotor, barpressing, eating, and drinking behavior exhibits attenuated circadian patterns in old animals (Ingram et al., 1982). Our present data do not support the view that age-related deficiencies in circadian functions reflect a loss of circadian periodicity in the suprachiasmatic nucleus. Turek et al. (1984) have reported that partial destruction of the suprachiasmatic nuclei of hamsters results in a partial inhibition of normal neuroendocrine-gonadal function. Thus, aging may involve a partial diminution of circadian function of the suprachiasmatic nucleus in rats without the total elimination of detectable GU rhythmicity. Alternatively, it is possible that a more detailed temporal analysis of GU in the suprachiasmatic nucleus could reveal subtle changes in the timing of activity in the neural pacemaker area.

We also observed a diurnal rhythm in GU in the pineal gland. Many pineal functions exhibit circadian periodicity in young rats. Pineal melatonin (Reiter et al., 1980) and norepinephrine (Greenberg and Weiss, 1978) concentrations increase during the dark; the density of $\beta$-adrenergic receptors decreases during the dark (Greenberg and Weiss, 1978). The GU rhythm was maintained in old ovariectomized rats and thus does not reflect the age-related changes in pineal function reported by others (Greenberg and Weiss, 1978; Reiter et al., 1980).

We observed decrements in GU in several areas of the hy-

Table 3. LH and PRL concentrations in young and old rats during the light and during the dark

\begin{tabular}{|c|c|c|c|c|c|c|c|}
\hline & \multicolumn{2}{|c|}{ Young (3-4 months) } & \multicolumn{2}{|c|}{ Old (18-21 months) } & \multicolumn{3}{|c|}{ Values of $p$ from ANOVA } \\
\hline & Light & Dark & Light & Dark & $\overline{\text { Age }}$ & Time & $A \times T$ \\
\hline LH-RP-2 (ng/ml) & $14.3 \pm 1.57^{a}$ & $12.8 \pm 1.96$ & $6.6 \pm 1.25$ & $7.1 \pm 1.45$ & 0.001 & NS & NS \\
\hline PRL-RP-2 (ng/ml) & $7.7 \pm 2.01$ & $8.7 \pm 2.23$ & $10.1 \pm 1.48$ & $10.21 \pm 2.32$ & NS & NS & NS \\
\hline
\end{tabular}

${ }^{a}$ Mean $\pm \mathrm{SE}(n=4-6)$. 
pothalamus that are intimately involved in reproductive function. Thus, changes in metabolic activity may be related to deteriorating reproductive function. This observation supports the finding that oxygen consumption is lower in the hypothalamus of 27-month-old than of 4-month-old Long-Evans rats of both sexes (Peng et al., 1977). Peng et al. (1977) observed that age-related metabolic deficits were present in old castrated/hypophysectomized male rats, in contrast to young rats, which suggests that the primary changes were in the brain tissue itself and were not secondary to altered gonadotropin and sex hormone levels. These age-related metabolic decrements may reflect alterations in neurotransmitter concentrations, turnover rates, and receptors in hypothalamic areas (Wise, 1983; Finch et al., 1984; Cohen-Becker and Wise, 1985; Weiland and Wise, 1986). In addition, they may indicate functional deficits that lead to decreased concentrations of hypothalamic releasing hormones (Wise and Ratner, 1980; Pekary et al., 1984).

Several lines of evidence suggest that the integrity of the suprachiasmatic preoptic, medial preoptic, suprachiasmatic, and paraventricular nuclei is critical to cyclic reproductive function in the young female. Estrous cyclicity ceases when the medial basal hypothalamus is isolated from these anterior hypothalamic structures (Halasz, 1969), when anterior hypothalamic areas are destroyed by electrolytic lesions (Brown-Grant and Raisman, 1977), or when hypothalamic neurotransmitters are depleted by administration of neurotoxins (Clifton and Sawyer, 1979; Walker et al., 1980). Attenuated preovulatory LH surges and the decreased ability of estradiol to induce LH surges have been correlated with the lack of diurnal rhythmicity in norepinephrine turnover rates in the suprachiasmatic and medial preoptic nuclei (Wise, 1982, 1984). Together, these data strongly suggest that decreased $\mathrm{GU}$ in these brain areas reflects changes in several neural parameters.

The lack of change in GU in all areas of the median eminence that we examined was unexpected, since several investigators have reported decreased neurotransmitter and hormonal function in this area of the brain. Thus, changes in turnover rates of catecholamines (Simpkins et al., 1977; Demarest et al., 1980; Estes and Simpkins, 1984) and serotonin (Simpkins et al., 1977) and of luteinizing hormone-releasing hormone (LHRH) concentrations in the median eminence (Wise and Ratner, 1980) of old rats are apparently not reflected in GU. There are 2 possible reasons for our findings. First, Mata et al. (1980) have reported that changes in cerebral glucose utilization are more closely linked to changes in activity of the sodium pump than to changes in neurosecretory activity. Therefore, it is possible that age-related changes in median eminence functions may be confined to its neurosecretory aspects, as opposed to its sodiumpump activity. Second, there is evidence that glucose may not be the primary substrate for energy metabolism in brain areas outside of the blood-brain barrier (Vannucci and Hawkins, 1983). Thus, oxidative metabolism in the median eminence could change in old rats without a concomitant change in GU.

Previous studies have demonstrated diminished GU in the cerebral cortex, corpus callosum, hippocampus, and striatum of old rats (Smith et al., 1980; London et al., 1981; Gage et al., 1984). However, the significance of these age-related changes have been questioned in a recent report showing an age-related decrease in the lumped constant in male Fischer 344 rats (Takei et al., 1986). Nonetheless, we found significant decreases in GU in the motor and somatosensory areas of the cerebral cortex, corpus callosum, and striatum. Changes in sensorimotor func- tion have been correlated with axonal dystrophy in these brain areas (Fujisawa and Shiraki, 1978). The GU decreases in these brain areas are consistent with such neuropathological changes. Various age-related neurochemical changes in the rat striatum have been reported. These include decreases in the densities of dopamine receptors (Joseph et al., 1978), dopamine sensitivity of adenylate cyclase (Puri and Volicer, 1977), and the activities of tyrosine hydroxylase (McGeer et al., 1971) and choline acetyltransferase (Meek et al., 1977). Thus, the decrease in striatal GU may be related to altered neurotransmitter function in this brain area.

In summary, these results demonstrate that age-related decrements in GU occur in several hypothalamic areas that are essential to normal cyclic reproductive function in the female rat. In particular, we observed changes in the GU in the suprachiasmatic nucleus, a critical neural pacemaker area. Together with evidence that several other hypothalamic neurochemical parameters exhibit deficits in the senescent hypothalamus, the data support the view that loss of cyclic reproductive function in the old female rat is related to changes in hypothalamic function.

\section{References}

Bremner, W. J., M. V. Vitiello, and P. N. Prinz (1983) Loss of circadian rhythmicity in blood testosterone levels with aging in normal men. J. Clin. Endocrinol. Metab. 56: 1278-1281.

Brown-Grant, K., and G. Raisman (1977) Abnormalities in reproductive function associated with the destruction of the suprachiasmatic nuclei in female rats. Proc. R. Soc. Lond. [Biol.] 198: 279-296.

Bryan, R. M., R. A. Hawkins, A. M. Mans, D. W. Davis, and R. B. Page (1983) Cerebral glucose utilization in awake unstressed rats. Am. J. Physiol. 244: C270-C275.

Clifton, D. K., and C. H. Sawyer (1979) LH release and ovulation in the rat following depletion of hypothalamic norepinephrine: Chronic vs. acute effects. Neuroendocrinology 28: 442-449.

Cohen-Becker, I. R., and P. M. Wise (1985) Age-related changes in serotonin turnover in the median eminence of ovariectomized estrogen-treated rats. Soc. Neurosci. Abstr. 11: 951.

Demarest, K. T., G. D. Riegle, and K. E. Moore (1980) Characteristics of dopamine neurons in the aged male rat. Neuroendocrinology 31 . 222-227.

Estes, K. S., and J. W. Simpkins (1984) Age-related alterations in dopamine and norepinephrine activity within microdissected brain regions of ovariectomized Long-Evans rats. Brain Res. 298: 209-218.

Everett, J. W., C. H. Sawyer, and J. E. Markee (1949) Neurogenictiming factor in control of the ovulatory discharge of $\mathrm{LH}$ in the cyclic rat. Endocrinology 44: 234-250.

Finch, C. E. (1973) Catecholamine metabolism in the brains of ageing male mice. Brain Res. 52: 261-276.

Finch, C. E., L. S. Felicio, C. V. Mobbs, and J. F. Nelson (1984) Ovarian and steroidal influences on neuroendocrine aging processes in female rodents. Endocr. Rev. 5: 467-497.

Fujisawa, K., and H. Shiraki (1978) Study of axonal dystrophy. I. Pathology of the neuropil of the gracile and the cuneate nuclei in ageing and old rats: A stereological study. Neuropathol. Appl. Neurobiol. 4: $1-20$.

Fuxe, K., K. Andersson, T. Hökfelt, L. F. Agnati, S. O. Ogren, and P. Eneroth (1978) Prolactin-monoamine interactions in rat brain and their importance in regulation of LH and prolactin secretion. In Progress in Prolactin Physiology and Pathology, C. Robyn and M. Harter, eds., pp. 95-109, Elsevier, Amsterdam.

Gage, F. H., P. A. T. Kelly, and A. Björklund (1984) Regional changes in brain glucose metabolism reflect cognitive impairments in aged rats. J. Neurosci. 4: 2856-2865.

Greenberg, L. H., and B. Weiss (1978) $\beta$-Adrenergic receptors in aged brain: Reduced number and capacity of pineal gland to develop supersensitivity. Science 201: 61-63.

Halasz, B. (1969) The cndocrine effects of isolation of the hypothalamus from the rest of the brain. In Frontiers in Neuroendocrinology, 
W. F. Ganong and L. Martini, eds., pp. 307-342, Oxford U. P., New York.

Ingram, D. K., E. D. London, and M. A. Reynolds (1982) Circadian rhythmicity and sleep: Effects of aging in laboratory rats. Neurobiol Aging 3: 287-299.

Joseph, J. A., R. E. Berger, B. T. Engel, and G. S. Roth (1978) Agerelated changes in the nigrostriatum: $A$ behavioral and biochemical analysis. J. Gerontol. 33: 643-649.

London, E. D., S. M. Nespor, M. Ohata, and S. I. Rapoport (1981) Local cerebral glucose utilization during development and aging of the Fischer-344 rat. J. Neurochem. 37: 217-221.

Mata, M., D. J. Fink, H. Gainer, C. B. Smith, L. Davidsen, H. Savaki, W. J. Schwartz, and L. Sokoloff (1980) Activity-dependent energy metabolism in rat posterior pituitary primarily sodium pump activity. J. Neurochem. 34: 213-215.

McGeer, E. G., H. C. Fibiger, P. L. McGeer, and V. Wickson (1971) Aging and brain enzymes. Exp. Gerontol. 6: 391-396.

Meek, J. L., L. Bertilsson, D. L. Cheney, G. Zsilla, and E. Costa (1977) $\Lambda$ ging-induced changes in acetylcholine and serotonin content in discrete brain nuclei. J. Gerontol. 32: 129-131.

Miller, N. E., and R. T. Bartus (1982) Sleep, sleep pathology and psychopathology in later life: A new research frontier. Neurobiol. Aging 3: 283-286.

Mosko, S. S., G. F. Erickson, and R. Y. Moore (1980) Dampened circadian rhythms in reproductively senescent female rats. Behav. Neurol. Biol. 28: 1-14.

Namba, H., and L. Sokoloff (1984) Acute administration of high doses of estrogen increases glucose utilization throughout brain. Brain Res. 291: 391-394.

Niswender, G. D., A. R. Midgley, S. E. Monroe, and L. E. Reichert (1969) Radioimmunoassay for rLH with anti-ovine LH serum and ovine LH-131. Proc. Soc. Exp. Biol. Med. 128: 807-811.

Paxinos, G., and C. Watson (1982) The Rat Brain in Stereotaxic Coordinates, Academic, New York.

Pekary, A. E., H. E. Carlson, T. Yamada, B. Sharp, P. G. Walfish, and J. M. Hershman (1984) Thyrolropin-releasing hormone levels decrease in hypothalamus of aging rats. Neurobiol. Aging 5: 221-226.

Peng, M.-T., Y.-I. Peng, and F.-N. Chen (1977) Age-dependent changes in oxygen consumption of the cerebral cortex, hypothalamus, hippocampus, and amygdaloid in rats. J. Gerontol. 32: 517-522.

Puri, S., and L. Volicer (1977) Effect of aging on cyclic AMP levels and adenylate cyclase and phosphodiesterase activities in the rat corpus striatum. Mech. Ageing Dev. 6: 52-58.

Reiter, R. J., B. A. Richardson, B. N. Johnson, B. N. Ferguson, and D. T. Dinn (1980) Pineal melatonin rhythm reduction in aging Syrian hamsters. Science 210: 1372-1374.

Schwartz, W. J., L. C. Davidsen, and C. B. Smith (1980) In vivo metabolic activity of a putative circadian oscillator, the rat suprachiasmatic nucleus. J. Comp. Neurol. 189: 157-167.
Selmanoff, M. K., and P. M. Wise (1981) Decreased dopamine turnover in the median eminence in response to suckling in the lactating rat. Brain Res. 212: 101-115.

Simpkins, J. W., G. P. Mueller, H. H. Huang, and J. Meites (1977) Evidence for depressed catecholamine and enhanced serotonin metabolism in aging male rats. Possible relation to gonadotropin secretion. Endocrinology 100: 1672-1678.

Simpkins, J. W., P. S. Kalra, and S. P. Kalra (1981) Alterations in daily rhythms of testosterone and progesterone in old male rats. Exp. Aging Res. 7: 25-32.

Smith, C. B., C. Goochee, S. I. Rapoport, and L. Sokoloff (1980) Effects of ageing on local rates of cerebral glucose utilization in the rat. Brain 103: 351-365.

Sokoloff, L. (1983) Measurement of local glucose utilization and its use in localization of functional activity in the central nervous system of animals and man. Recent Prog. Horm. Res. 39: 75-126.

Sokoloff, L., M. Reivich, C. Kennedy, M. DesRosiers, C. Patlak, K. Pettigrew, O. Sakurada, and M. Shinohara $(1977){ }^{14} \mathrm{C}$-deoxyglucose method for the measurement of local cerebral glucose utilization: Theory, procedure and normal values in the conscious and anesthetized albino rat. J. Neurochem. 28: 897-916.

Takei, H., W. R. Fredericks, and S. I. Rapaport (1986) The lumped constant in the deoxyglucose procedure declines with age in Fischer344 rats. J. Neurochem. 46: 931-938.

lurek, F. W., J. Swann, and D. J. Earnest (1984) Role of the circadian system in reproductive phenomena. Recent Prog. Horm. Res. 40: 143-183.

Vannucci, S., and R. Hawkins (1983) Substrates of energy metabolism of the pituitary and pineal glands. J. Neurochem. 41: 1718-1725.

Walker, R. F., R. I. Cooper, and P. S. Timiras (1980) Constant estrus: Role of rostral hypothalamic monoamines in development of reproductive dysfunction in aging rats. Endocrinology 107: 249-255.

Weiland, N. G., and P. M. Wise (1986) Effects of age on $\beta_{1^{-}}$and $\beta_{2}-$ adrenergic receptors in the brain assessed by quantitative autoradiography. Brain Res. 398: 305-312.

Wise, P. M. (1982) Norepinephrine and dopamine activity in microdissected brain areas of the middle-aged and young rat on proestrus. Biol. Reprod. 27: 562-572.

Wise, P. M. (1983) Aging of the female reproductive system. In Review of Biological Research in Aging, M. Rothstein, ed., pp. 195-222, Liss, New York.

Wise, P. M. (1984) Estradiol-induced daily LH and prolactin surges in young and middle-aged rats: Correlations with age-related changes in pituitary responsiveness and catecholamine turnover rates in microdissected brain areas. Endocrinology 115: 801-809.

Wise, P. M., and A. Ratner (1980) Changes in hypothalamic LHRH, plasma LH, FSH, estradiol and progesterone after ovariectomy in old and young rats. Neuroendocrinology 30: 15-19. 